\title{
Tryptophan-like fluorescence as a measure of microbial contamination risk in groundwater
}

Saskia Nowicki $^{\mathrm{a}}$, Dan J Lapworth ${ }^{\mathrm{b}}$, Jade S T Ward ${ }^{\mathrm{bc}}$, Patrick Thomson $^{\mathrm{a}}$, Katrina Charles ${ }^{\mathrm{a}}$

${ }^{a}$ University of Oxford, School of Geography and the Environment, Oxford, OX1 3QY, UK

${ }^{\mathrm{b}}$ British Geological Survey, Maclean Building, Wallingford, OX10 8BB, UK

${ }^{c}$ University of Surrey, Department of Civil and Environmental Engineering, Guildford, GU2 7XH, UK

Corresponding author: Saskia Nowicki (saskia.nowicki@ ouce.ox.ac.uk) 


\section{Tryptophan-like fluorescence as a measure of microbial contamination risk in groundwater}

Saskia Nowicki, Dan J Lapworth, Jade S T Ward, Patrick Thomson, Katrina Charles

Microbial water quality is frequently assessed with a risk indicator approach that relies on Escherichia coli. Relying exclusively on E. coli is limiting, particularly in low-resource settings, and we argue that risk assessments could be improved by a complementary parameter, tryptophan-like fluorescence (TLF). Over two campaigns (June 2016 and March 2017) we sampled 37 water points in rural Kwale County, Kenya for TLF, E. coli and thermotolerant coliforms (total $\mathrm{n}=1,082$ ). Using three World Health Organization defined classes (very high, high, and low/intermediate), risk indicated by TLF was not significantly different from risk indicated by $E$. coli $(\mathrm{p}=0.85)$. However, the TLF and E. coli risk classifications did show disagreement, with TLF indicating higher risk for $14 \%$ of samples and lower risk for $13 \%$ of samples. Comparisons of duplicate/replicate results demonstrated that precision is higher for TLF (average relative percent difference of duplicates $=14 \%$ ) compared to culture-based methods (average RPD of duplicates $>=26 \%$ ). Additionally, TLF sampling is more practical because it requires less time and resources. Precision and practicality make TLF well-suited to high-frequency sampling in low resource contexts. Interpretation and interference challenges are minimised when TLF is measured in groundwaters, which typically have low dissolved organic carbon, relatively consistent temperature, negligible turbidity and $\mathrm{pH}$ between 5 and 8 . TLF cannot be used as a proxy for E. coli on an individual sample basis, but it can add value to groundwater risk assessments by improving prioritization of sampling and by increasing understanding of spatiotemporal variability. 
Key words: tryptophan-like fluorescence; microbial risk assessment; field methods; drinking water; groundwater quality

\section{Introduction}

Improving water quality is crucial to the United Nations' Sustainable Development Goal 6.1, ensuring universal access to safely managed drinking water. Globally, $25 \%$ of people lack access to water free from microbial contamination (JMP, 2017); in Africa, the estimate doubles to $50 \%$ (Bain et al., 2014). The resulting disease burden is difficult to quantify but for low- and middle-income countries, half a million diarrheal deaths recorded in 2012 were attributed to microbially contaminated water (Prüss-Ustün et al., 2014). Beyond mortality, there are persistent physical and cognitive morbidity impacts, especially for children (Guerrant et al., 2002).

Groundwater usually has better microbial quality compared to surface water, but it can be vulnerable to anthropogenic impact. Regional estimates of groundwater microbial contamination range from $78 \%$ to $97 \%$ of unprotected water points and $10 \%$ to $41 \%$ of boreholes (Bain et al., 2014). This contamination has large repercussions because direct access to groundwater accounts for a third of global water supply $(27.3 \%$ protected, $7.4 \%$ unprotected), coming second only to piped networks (Bain et al., 2014). Work is ongoing to better understand and manage groundwater contamination and risk assessment is central to that effort (Murphy et al., 2017).

Assessment of microbial contamination is ultimately concerned with the presence of pathogens; however, sampling for pathogens is difficult: there are many types, they frequently occur in low concentrations, and differentiating between infectious and non-viable organisms is challenging (Cangelosi and Meschke, 2014). As a result, an indicator approach 
using coliform bacteria has been common for the last century. As a common enteric species that is relatively easy to culture, Escherichia coli (E. coli) is the preferred indicator (WHO, 2011).

E. coli are thermotolerant coliforms (TTCs), meaning that they are culturable and ferment lactose at $44^{\circ} \mathrm{C}$. In addition to Escherichia, the TTC subgroup also includes three other genera (Klebsiella, Enterobacter and Citrobacter). The ratio of E. coli to all TTCs is variable (Garcia-Armisen et al., 2007; Hamilton et al., 2005; WHO, 2012), but it is not uncommon for TTCs to be used as a proxy for E. coli (WHO, 2011). For risk assessment purposes, E. coli (or TTC) results are often interpreted by way of a four-tier ordinal risk classification scheme based on either most probable number (MPN) or colony forming units (CFU) per $100 \mathrm{~mL}$ (WHO, 2011). The risk classes are low (<1), intermediate (1-10), high (11-100), and very high $(>100)$.

Although widely regarded as a successful approach, use of $E$. coli is costly in terms of time requirement and consumables. Furthermore, as explained later in this section, the absence of E. coli in drinking water cannot be relied upon as a certain indication of safety. In this study we show how an additional parameter, tryptophan-like fluorescence (TLF), may help address these disadvantages. The TLF peak (centred on excitation/emission at $275 / 340 \mathrm{~nm}$ ) is so named because it reflects concentrations of compounds that have similar fluorescence characteristics as the amino acid tryptophan. The constituents that produce TLF are fractionated into three size classes (Baker et al., 2007). The $>2.7 \mu \mathrm{m}$ fraction includes particulate organic matter that cause a detrimental apparent signal through scattering of light. The middle size class $(0.2 \mu \mathrm{m}$ to $2.7 \mu \mathrm{m})$ includes bacteria, which contribute directly to TLF. The remaining $<0.2 \mu \mathrm{m}$ fraction are free-form proteinaceous materials produced by bacterial metabolism. TLF can be measured in-situ using ultra-violet fluorimetry and is associated with 
microbial breakdown of labile, or bioavailable, organic carbon (Elliott et al., 2006; Fox et al., 2017; Hudson et al., 2008). Although labile carbon occurs naturally, faecally contaminated water is characterised by intense TLF peaks that can be identified in contrast to natural baseline levels (Hudson et al., 2007).

This is the first groundwater study to compare TLF with E. coli specifically, but previous studies have found it correlated with faecal Streptococcus and Clostridium bacteria (Lapworth et al., 2008), TTCs in groundwaters (Sorensen et al., 2015a, 2016), E. coli in surface waters (Baker et al., 2015; Cumberland et al., 2012), and biological oxygen demand in organic waste streams (Carstea et al., 2016; Hudson et al., 2008). These studies help build a case for the utility of TLF, but do not provide definitive insight into its relationship with pathogens. The relationships between long-used indicators and pathogens remain unclear because direct comparisons are difficult and rare (Ferguson et al., 2012; Sorensen et al., 2015b). In lieu of direct comparisons, one way to consider how TLF and E. coli relate to pathogens is by referencing established criteria for an 'ideal' microbial contamination indicator.

The World Health Organization (WHO) stipulates five criteria for indicators, they should 1) be universally present in faeces at higher concentrations than pathogens; 2) persist in the environment and respond to treatment in a similar manner to pathogens but 3) not be pathogenic; 4) be simply and inexpensively detected; and 5) not multiply in natural waters (WHO, 2011). The first criterion is well met by both $E$. coli and TLF. The second, less so; $E$. coli can mimic physiologically similar pathogens but viruses and protozoa have different transport patterns and superior environmental survival times (Leclerc et al., 2001; Osborn et al., 2004). Consequently, the absence of E. coli in groundwater does not guarantee its safety. In contrast, TLF in groundwater is strongly associated with $<0.2 \mu \mathrm{m}$ material, potentially 
giving it a size-based advantage as a more mobile and, therefore, conservative indicator of microbial contamination (Sorensen et al., 2016). There is some evidence that TLF is also more persistent in the environment than culturable TTCs (Sorensen et al., 2015a).

TLF is not specific to any one organism and meets the third criterion of being nonpathogenic. The fourth criterion stipulates simple, inexpensive detection. Typical E. coli detection methods rely on a particular enzyme ( $\beta$-glucuronidase) and require 18 to 48 hours, sterile conditions, technical training and a range of consumables. In-situ fluorimetry has much lower variable cost by providing immediate results with minimal process steps, training and consumables.

Finally, the fifth criterion, not multiplying in the environment, is not met by E. coli or TLF. That non-Escherichia coliforms are present in the environment is a long-standing criticism of their use as indicators (Leclerc et al., 2001). For E. coli, many maintain that environmental populations are limited and usually out-competed (WHO, 2012) but studies have reported $E$. coli survival and regrowth within tropical and temperate soils (Brennan et al., 2010a, 2010b; Fujioka et al., 1998; Solo-Gabriele et al., 2000), sediments (Haller et al., 2009), water (Pote et al., 2009), and handpumps (Ferguson et al., 2011). For TLF, natural baseline levels are expected when microbial communities and labile carbon are present, but differentiating between baseline and contaminated conditions is possible because faecal TLF concentrations are high relative to baseline uncontaminated waters (Baker, 2001; Sorensen et al., 2015a).

Although less than ideal, it is widely held that using E. coli as an indicator is justified; we do not disagree. We argue that, being well-matched to the discussed criteria, TLF has potential as a complementary parameter. TLF will not replace $E$. coli as an indicator, but it has significant practical advantages for rapid screening and monitoring of microbiological groundwater quality. In this study we investigate the usability and effectiveness of in-situ 
fluorimetry in comparison with cultured faecal indicator bacteria. Our comparison focusses on agreement and precision of results.

We used two different methods for determining E. coli concentrations in our samples and, since other studies of TLF in groundwater have used TTCs for comparison, we also analysed for TTCs to understand how they compare to E. coli in our context. Based on comparison with E. coli results, we determined thresholds for grouping TLF into corresponding ordinal risk classes. We used paired ordinal logit cumulative link models to assess the level of agreement between the risk classifications generated by the different methods. Our second aim was to determine the relative precision of the methods. We did this by inclusion of duplicates and replicates in our sampling design. Drawing from our findings and experience in the field, as well as the wider literature, we then discuss how TLF can complement E. coli sampling and add value to risk assessments.

\section{Methods}

Sampling occurred in rural Kwale County, Kenya, at the end of the wet season (June 2016) and before the rains at the end of the dry season (March 2017). Thirty-seven water points (WPs) were selected from a total of eighty surveyed sites. They were selected to capture a range of contamination conditions and, therefore, included three WP types and a range of sanitary inspection scores (Table 1). Scores were calculated using the criteria presented in CAWST 2013, which is based on WHO guidance (WHO, 2012). Additional criteria for selection were that the WPs drew from unconfined groundwater, were used as drinking water sources, and were not chlorinated. The WPs spanned three geological units including Pleistocene coral reef, Pleistocene Kilindini sands, and Pliocene Margarini sands (Caswell and Baker, 1953; Mumma et al., 2011). 


\subsection{Sample collection and analysis}

Sampling was designed to capture both temporal and spatial variability. Eight WPs (two open wells [OWs], three covered wells with handpumps [CWs], and three boreholes with handpumps $[\mathrm{BHs}]$ ) were visited daily (at the same time each day) over three weeks in June 2016. Five were again visited daily over two weeks in March 2017. Two of the original OWs and one $\mathrm{BH}$ were not sampled in 2017 because they were dry due to a low water table. However, an additional thirty WPs (ten OWs, eleven CWs, nine BHs) were each visited once for sampling.

All the sampled WPs were in regular use and roughly 300 litres were pumped to flush the boreholes prior to sampling. At the OWs, samples were drawn with buckets and ropes. Each site had its own bucket and rope set and they were triple-rinsed with distilled bottled water prior to sampling to minimise the potential influence of contamination from hands or dust. Daily field and laboratory blank samples were analysed for quality control to verify that secondary contamination and cross-contamination between sites was avoided.

As detailed in Sections 2.1.1 and 2.1.2, four methods of analysis were used to assess microbial contamination including in-situ fluorimetry, compartmental bag tests (CBTs), and membrane filtration plate counts (PCs) with two different broths (Table 2).

Across all the methods, a total of 1,082 samples were tested. Due to time, budget and equipment constraints, the number of samples analysed by each method varied. Nevertheless, the sampling design enabled comparisons of TLF and $E$. coli by CBT method ( $\mathrm{n}=162), E$. coli by PC method $(\mathrm{n}=70)$, and TTCs $(\mathrm{n}=81)$. Duplicate and replicate testing was also included for each method to assess environmental- and method-induced variability, respectively. Duplicate samples were collected from the same WP within minutes of each 
other and laboratory replicates were different aliquots from a single sample (there were no laboratory replicates for TLF since it was measured in-situ).

\subsubsection{TLF sampling}

For TLF, in-situ measurement was done using three commercially available UviLux probes, LED UV-based portable fluorimeters that measures fluorescence intensity at $280 \pm 30$ / $360 \pm 50 \mathrm{~nm}$ excitation/emission wavelength pairs. The probes express TLF intensity as an equivalent concentration of dissolved tryptophan in parts per billion with a detection limit of $0.01 \mathrm{ppb}$. Prior to sampling, linear calibration equations were determined for each probe using standards of $0,0.5,1,2$, and $5 \mathrm{ppb}$ prepared from L-tryptophan (Acros Organics, USA) in deionized, sterile water. Post-sampling laboratory work confirmed no calibration drift.

We followed manufacturer recommended sampling protocols, which have been used in previous groundwater studies (Sorensen et al., 2015, 2016, 2018a). Approximately three litres of unfiltered water were pumped or poured into a container kept a black box to prevent ambient light from interfering with the measurement. The container we used was made from stainless-steel and was cleaned with ethanol and triple-rinsed with sample water prior to each measurement. Measurement was immediate with readings recorded for approximately three minutes. The probe and its sensor window were always kept clean and clear and care was taken to ensure that air bubbles did not form on the sensor window during sampling.

\subsubsection{Bacteria sampling}

Collection and analysis of the bacterial samples was carried out in accordance with published guidance from the test manufacturers (see Table 2). Samples were collected in sterile 
purpose-made bags and immediately stored in a cooler box with ice-packs. They were transported and processed to begin incubation within two to five hours.

The CBT method from Aquagenx was chosen for E. coli sampling based on its low cost and sample processing time. The CBT approach is relatively new and it uses a statistically derived most probable number (MPN) table to estimate E. coli concentrations (Gronewold et al., 2017). In contrast, the more established PC methods produce results in colony forming units (CFU). We had reason to believe that CBT method performance would be comparable to membrane filtration PC methods (Stauber et al., 2014; Wang et al., 2017), but to increase confidence we included the m-ColiBlue24 method to compare against our CBT results. Both methods measure $E$. coli based on production of $\beta$-glucuronidase.

We also included the DelAgua method for measuring TTCs using laurel sulphate broth and incubation at $44^{\circ} \mathrm{C}$. We did this for comparative purposes because the previous studies of TLF in groundwater have used TTCs not E. coli specifically (Sorensen et al., 2015a, 2016, 2018a).

\subsubsection{Physicochemical sampling}

$\mathrm{pH}$, temperature, and turbidity were measured in-situ for all samples. This was necessary because in certain ranges these parameters can interfere with TLF signal:

- $\quad$ Between pH 5 and 8, fluorescence intensity is minimally affected ( $\pm 3 \%)$, but in more acidic waters ( $\mathrm{pH}<4.5$ ) signal quenching can be up to $15 \%$ (Reynolds, 2003).

- Increasing temperature heightens collisional quenching, thereby reducing fluorescence intensity (Wehry, 1973) and attenuating TLF signal (Khamis et al., 2015). 
- Turbidity over 50 NTU attenuates TLF signal, whereas fine particulates like suspended clay and organics can cause a detrimental apparent signal when turbidity is less than 50 NTU (Baker et al., 2007; Khamis et al., 2015).

We needed to determine if it would be necessary to use correction algorithms (as in Bieroza and Heathwaite, 2016; Khamis et al., 2015) and / or if we would need to filter turbidity out of our samples prior to measuring TLF. We used a combo $\mathrm{pH}$ and temperature meter from Hanna Instruments (HI-98129) and a portable microprocessor-based turbidity meter from ELE International (range 0 to 1000 NTU). Calibration of the meters was checked against standard solutions bi-weekly during sampling.

\subsection{Data analysis}

Before commencing analysis of the TLF data, the $\mathrm{pH}$, temperature and turbidity data were summarised to confirm lack of interference. The raw TLF data was then corrected for probe sensitivity using laboratory-determined linear equations (see Section 2.1.1). Negative TLF values indicated concentrations below the probe's detection limit and were amended to equal that limit, $0.01 \mathrm{ppb}$.

Non-parametric statistics were used to accommodate ordinal data, reduce the impact of outliers and because continuous data were not normally distributed. Kendall's $\tau$ tie-corrected rank correlations (Kendall, 1938) were used for initial two-way comparisons of the TLF and bacteria results from all methods. Further analysis grouped the bacteria results according to the WHO ordinal four-tier risk classification scheme (see Section 1 paragraph 4).

The TLF results were compared to the ordinal risk class data from E. coli (CBT) using Kruskal-Wallis rank sum tests (Hollander et al., 2014). The TLF results were also visually 
compared to the CBT results using box-and-whisker plots. Based on these plots, the TLF results were grouped into ordinal categories.

The $\mathrm{R}$ package 'ordinal' ( $\mathrm{R}$ version 3.4.4) was used to assess pairwise agreement of risk classification results between the bacteria methods and TLF results through paired ordinal logit cumulative link models (CLMs) with flexible, unstructured thresholds (Agresti, 2010, 1992; Christensen, 2015). Likelihood ratio tests with an asymptotic $\chi^{2}$ distribution were used to assess whether the models met the proportional odds assumption (that the relationship between two methods being compared is consistent across risk classes). Nominal Monte Carlo symmetry tests were also used for pair-wise risk class comparisons to confirm the CLM results.

For each of the four methods, precision was assessed first by relative percent difference: $R P D=\left|\frac{x-y}{(x+y) / 2}\right| \times 100 \%$, where $x$ and $y$ represent duplicate or replicate pairs, and second by the proportion of pairs indicating equal risk. Since laboratory replicates are not available for TLF, replicate variability was assessed by the standard deviation of auto-logged measurements, which were recorded for each 2017 sample at a rate of one reading every second.

Finally, temporal variability of results was assessed using time series graphics and geometric means of samples from the wet season versus the dry season.

\section{Results}

\subsection{Confirming negligible interference}

$\mathrm{pH}$, temperature and turbidity were within ranges that have negligible effects on TLF signal. Sample turbidity never exceeded 50 NTU ( $88 \%$ of samples $<5$ NTU, $98 \%<20$ NTU) and pH 
was typically neutral or circumneutral (mean 7.0; SD 0.3). Temperature ranged from 27 to $32^{\circ} \mathrm{C}$ (mean $29.3^{\circ} \mathrm{C}$; SD $0.9^{\circ} \mathrm{C}$ ) and the calibration curves used for data correction were generated at $30^{\circ} \mathrm{C}$. No temperature correction was made because laboratory work showed temperature effects were minimal over the range encountered, especially at low TLF concentrations (Figure 1).

\subsection{Comparing TLF and cultured bacteria}

The TLF and bacteria results were correlated. Significant monotonic relationships were indicated by Kendall's $\tau$ tie-corrected rank correlations $(p<0.001)$. However, scatter was observed in all the relationships (correlation coefficients shown in Table 3). Due to this scatter and since microbial water quality sampling is concerned with assessing risk, further analyses grouped the bacteriological data by risk classes.

The TLF results were compared to the risk class data from E. coli $(\mathrm{CBT} ; \mathrm{n}=162)$. We tried to test for difference in the median TLF values among the E. coli (CBT) risk classes. KruskalWallis rank sum tests indicated significant differences $\left(\chi^{2}=93 p<0.001\right)$; however, the shape and spread of results in each risk class were different enough that the assumption of equal distribution was violated. This means that the Kruskal-Wallis test confirmed significantly different distributions of TLF results in each risk class but could not compare medians.

TLF did not differentiate between the low and intermediate risk classes, as revealed by visual assessment of box-and-whisker plots comparing the TLF results by E. coli (CBT) risk classes (Figure 2). Without any information on pathogen presence, samples with low TLF and no $E$. coli (those classified as low risk based on CBT results) were interpreted as representing baseline TLF levels under natural, uncontaminated conditions. The results indicate that TLF 
cannot differentiate between intermediate contamination risk and baseline conditions, noting that there was limited data for the intermediate risk class $(n=12)$.

The TLF results were divided into three groups using the thresholds of 1 and $3.9 \mathrm{ppb}$ indicated by the horizontal lines on Figure 2. These grouped results were then compared to corresponding E. coli (CBT) results coded as low/intermediate, high and very high risk. There was no significant difference in the probability that TLF would indicate higher or lower risk than $E$. coli $(\mathrm{CBT})$. This result was generated using a paired cumulative link model (CLM), which assesses the likelihood that the different methods would produce systematically different risk classifications for samples taken from the same WP within minutes of each other. The CLM test is directional, producing estimates of either a shift up (positive estimate) or down (negative estimate) on the ordinal risk scale. In comparing TLF and $E$. coli $(\mathrm{CBT})$ the effect estimate was only 0.01 (standard error of $0.21 ; \mathrm{p}=0.98$ ).

Additional CLMs were run to compare the E. coli (CBT) and TLF results with the E. coli (PC) and TTC results (Table 3). Compared to both E. coli (CBT) and TLF, the TTC method was found to have a significantly higher probability of classifying samples as higher risk. In contrast, the two E. coli methods (CBT and PC) had no significant difference in their classifications of samples. The TLF and E. coli (PC) comparison was borderline, possibly due to the lower sample size.

The effect estimates produced by the CLMs were consistent across the risk classes for all comparisons except a) TLF and E. coli (PC) and b) TTCs and E. coli (CBT). Consistency of effect estimates is determined using post-hoc likelihood ratio tests (LRTs). A significant LRT indicates that the effect estimate of a CLM must be interpreted as an average across the risk classes. The likelihoods of a) TTCs overestimating risk relative to E. coli (CBT) and b) TLF overestimating risk relative to $E$. coli $(\mathrm{PC})$ may not be the same when contamination is low 
versus when it is high. This lack of consistency may be due to unequal distribution of samples among the risk classes (for example see Figure 3a).

Nominal Monte Carlo symmetry tests help further explain the results of the CLM tests by assessing each defined $(n>0)$ intersection of risk classes separately (Table 3$)$. TTCs were confirmed to overestimate risk relative to E. coli (CBT) and TLF. Relative to E. coli (PC), TLF was found to overestimate risk only from low to medium $(\mathrm{p}<0.05)$, not from low to high $(\mathrm{p}=0.5)$ or medium to high $(\mathrm{p}=0.45)$. No significant differences $(p>0.05)$ were found in the contingency tables comparing the $E$. coli methods and TLF with $E$. coli (CBT). 
The key result from the CLM tests was that risk indicated by TLF samples was not significantly different from risk indicated by E. coli (CBT) samples, except that TLF gives resolution at three risk levels instead of four. However, although there was no significant directional difference in the TLF and E. coli (CBT) results, there was considerable disagreement (Figure $3 b$ ). If the E. coli (CBT) risk classification results are used as a starting point, $14 \%$ of TLF samples indicated higher risk and 13\% indicated lower risk. Looking at each risk category individually, disagreement ranged from $17 \%$ to $30 \%$ (Table 4).

\subsection{Determining precision and temporal variability}

The TLF results were more precise than the bacteria results from all three methods. The TLF duplicates showed lower relative percent differences (RPDs) and better agreement between pairs than the duplicates or replicates of any of the bacteria methods (absolute RPDs shown in Figure 4). Agreement here is defined as the proportion of pairs that indicate the same risk class. For the TLF data this was based on the three groupings defined in Section 3.2. For each TLF sample, standard deviations were calculated for readings auto-logged approximately once per second for three minutes each. The average and median of these standard deviations were 0.04 and $0.03 \mathrm{ppb}$, respectively.

Timeseries analysis of the samples that were collected daily from the same WPs did not show any short-term patterns of change in TLF or E. coli (CBT) results. No relationship was found between water quality and rainfall events. There was insufficient information to isolate the effect of rainfall from other factors and a water level datalogger installed at one of the water points (TC06) showed that water table depth changed on a slower timescale than individual rain events (measured at a nearby automatic weather station). 
However, seasonal change was demonstrated by TLF and, to a lesser extent, E. coli (CBT). Seasonal geometric means of the TLF and E. coli (CBT) results were calculated for the five WPs where daily sampling was conducted in both sampling campaigns (Figure 5). Generally, the TLF results indicated less contamination in the wet season (positive RPD) - likely an effect of dilution. However, between the two sampling campaigns, one of the sites (TO07) was refurbished to reduce ingress of surface water and the TLF results indicated a reduction in contamination in the dry season (negative RPD), possibly due to increased protection of the well. Changes in water quality between the campaigns were more clear from the TLF results than from E. coli. This is consistent with the finding that TLF is a more precise measure.

\section{Discussion}

Internationally, focus is on finding a rapid E. coli detection method that reduces chances of error and improves capacity for understanding and communicating risk (UNICEF, 2017). However, the search for a simple, rapid risk assessment method need not focus exclusively on E. coli. TLF has the benefit of speed and other practical attributes, particularly when used for groundwater sampling, as discussed in Section 4.1. Despite many positives, however, TLF has important limitations (Section 4.2) and is better suited to certain contexts than others (Section 4.3).

\subsection{TLF is precise, rapid and practical for groundwater sampling}

The speed and in-situ application of fluorimetry reduces opportunities for analytical variability, resulting in greater precision. In contrast, for the bacteria methods, RPDs and level of agreement were similar between duplicate pairs and replicate pairs. This indicates that analytical variability rather than source material homogeneity was controlling sample 
precision. Analytical variability may derive in part from bacteria being unevenly distributed within samples. Even with agitation, bacteria exhibit small-scale $(<10 \mathrm{~cm})$ patchiness resulting from attachment to particles and aggregation amongst themselves (Kirchman et al., 1982). Furthermore, E. coli response to growth media and incubation conditions is variable (Chang et al., 1989; Leclerc et al., 2001). The CBT test approach also introduces analytical variability by statistically estimating results - this method is effective for large sample sizes but is less precise for individual samples.

In addition to precision, positive attributes of in-situ fluorimetry include that it is accessible with minimal training for non-technical users; provides quantified, easily displayed results, and has minimum process steps with no requirements for reagents, cold chains, sterilization or incubation. The probes are battery-powered, lightweight, portable, durable and waterproof. They require minimal consumables/packaging and no hazardous materials. The unit cost per probe is currently USD 5,000 but the expected lifespan is over 10 years and the cost will decrease if demand increases. Additionally, the variable cost of sampling is minimal.

As potentially interfering factors, $\mathrm{pH}$, temperature and turbidity could complicate the use of TLF in some conditions (see Section 2.1.3), but this is less likely when sampling groundwater. Unlike surface water, groundwater generally has low turbidity and slow changes in temperature. When temperature is relatively consistent, probe calibration is sufficient to account for thermal quenching (as in this study). Furthermore, the strongest thermal quenching is associated with larger $(>1.2 \mu \mathrm{m})$ fluorophores (Seredyńska-Sobecka et al., 2007). This suggests it may be a bigger issue for turbid surface waters than for typical groundwaters, in which TLF is primarily associated with $<2.7 \mu \mathrm{m}$ material: bacteria and their metabolites (Sorensen et al., 2016). 
Although we did not include metal ions in our sampling design, we note that they may also interfere with TLF. Metal ions are known to bind with dissolved organic matter and can, thereby, form complexes that dampen fluorescence. TLF quenching by addition of metal ions like $\mathrm{Cu}^{2+}$ and $\mathrm{Ni}^{2+}$ has been demonstrated through laboratory work (Tabak et al., 1989); however, fluorescence quenching has been shown to vary considerably in different sample waters and the extent of TLF quenching by metal ions in natural and even engineered environments is not well understood (Henderson et al., 2009; Yamashita and Jaffé, 2008). Reynolds and Ahmad (1995) and Heibati et al. (2017) found that metal ion concentration did not significantly alter TLF in samples taken from treated sewage effluent and a piped water distribution system, respectively.

\subsection{TLF is not an accurate E. coli proxy}

We estimated TLF thresholds that divide samples into groups corresponding with low/intermediate, high and very high $E$. coli risk classes, but were not able to distinguish intermediate risk from baseline conditions. Intermediate risk is still concerning from a health perspective because, although pathogen hazard is related to indicator concentration, pathogen concentrations vary widely at any given indicator concentration and some have minimum infective doses as low as a few cells (WHO, 2011; Schmid-Hempel, 2011). This is one reason why TLF is not recommended as a replacement for E. coli. Nevertheless, low-cost, practical, in-field methods are essential if water quality information is to be available to support decision-making in low resource settings (Bain et al., 2012).

Remembering that E. coli is itself an imperfect indicator, the value of TLF should not be anchored solely to its performance relative to $E$. coli. Understanding how TLF relates to $E$. coli is important, however, because it places TLF results within a familiar risk assessment 
framework. We found that TLF cannot determine presence/absence of E. coli but could differentiate samples with $>10$ or $>100$ E. coli/100mL. Our results indicate TLF thresholds of 1 and $3.9 \mathrm{ppb}$. However, these values and their associated rates of disagreement with $E$. coli results (Table 4) are not directly applicable beyond our study area.

Variability in the relationship between TLF and E. coli in different groundwaters makes evaluating performance between study areas challenging. Based on 564 surface and groundwater samples comparing TLF and TTCs from four different study areas, Sorensen et al (2018a) determined thresholds of 1.3 and $6.9 \mathrm{ppb}$. The differences between our thresholds and theirs may be partly due to the use of different data analysis methods, their inclusion of surface water as well as groundwater samples, and their use of TTCs instead of E. coli. Nevertheless, even with these factors held constant, one would expect varying relationships between TLF and E. coli because environmental factors like temperature, $\mathrm{pH}$ and turbidity impact the two parameters differently.

An additional environmental factor to consider is the concentration of humic substances. The TLF excitation/emission region has overlap with fluorescence from natural organic matter derived from soils (Lapworth et al., 2009; Stedmon et al., 2011). Water that is naturally rich in humic substances may have a stronger apparent TLF signal that does not correspond to higher microbial contamination risk (Sorensen et al., 2018b). However, interactions with humic-like substances can suppress protein-like fluorescence (Wang et al., 2015), which could potentially have the contrary effect of weakening apparent TLF. The relative strength of these effects is not well understood and is likely to vary in different contexts. Fortunately, in most European groundwaters, dissolved organic carbon is typically well below the levels expected from contaminated conditions (Gooddy and Hinsby, 2008), which will, therefore, be distinguishable from the natural baseline. This is expected to hold true for most groundwater 
at shallow and intermediate depths $(0-200 \mathrm{~m})$ globally, with some exceptions occurring in unconsolidated sedimentary systems where higher organic matter concentrations are likely (BGS-DPHE, 2001).

Comparisons of TLF results between campaigns should focus on differences from baseline rather than absolute TLF values. This means that sampling campaigns must include uncontaminated sites so that natural baseline ranges are captured. If comparison to E. coli is intended, sampling campaigns will also need to be designed to allow sufficient comparison between TLF and E. coli results so that context-specific thresholds can be established. Even with context-specific thresholds, it will not be appropriate to use TLF to predict $E$. coli concentrations on an individual sample basis.

Other substances that fluoresce in the TLF range include polycyclic hydrocarbons, pharmaceutically active compounds, and other pollutants from plastic, petrochemical, paper, leather and textile industrial processes (Carstea et al., 2016). Presence of these pollutants could potentially increase the likelihood that TLF overestimates risk relative to E. coli. Nevertheless, these substances pose health risks of their own and also indicate inadequate protection of groundwater sources.

\subsection{TLF can enhance pre-screening, monitoring and communication of risk}

Considering the advantages and challenges discussed, we recommend TLF for three applications: pre-screening, monitoring, and communication of risk. It is recommended for pre-screening because it enables larger datasets to be generated quickly to inform priorities for intervention or further investigation. Depending on the purpose of sampling, WPs with high TLF could immediately be considered high risk and not a priority for E. coli sampling (especially when coincident with high risk WP design/sanitary risk factors). E. coli sampling 
would be redundant in these cases because a) it is likely that elevated TLF coincides with elevated $E$. coli and b) there are multiple reasons why E. coli methods may underestimate risk so elevated TLF warrants high risk classification regardless of E. coli concentration. WPs with low TLF during pre-screening may warrant further investigation, especially when coupled with high sanitary inspection scores. Pre-screening with TLF could allow bacteriological testing to be prioritized more effectively.

TLF could also be considered for regulatory or surveillance monitoring. In some contexts, sampling frequency can be more important than having highly-accurate results (Levy, 2015). High-frequency monitoring is needed to identify changes in hazard that would otherwise be obscured by short-term fluctuations or missed entirely by low-frequency sampling designs (Okotto-Okotto et al., 2015; Levy et al., 2009; Boehm, 2007; Roser and Ashbolt, 2007). Precision, coupled with low cost of sampling, make in-situ fluorimetry well-suited for ongoing monitoring efforts to understand trends and spikes in risk. For example, based on stronger correlations with $E$. coli, fluorescent dissolved organic matter was shown to be more effective than turbidity for online monitoring of influent (groundwater) to a public drinking water supply in the UK (Sorensen et al., 2018b). Method-derived variability is unlikely to obscure changing TLF concentrations in WPs, which could be caused by a variety of drivers like seasonal change in recharge regime, land-use change, interventions to improve WP protection, or nearby construction of potentially contaminating facilities like latrines or livestock holdings (Lawrence et al., 2001).

Finally, a third potential application of TLF relates to communicating risk. A formal assessment of TLF as a means to communicate risk to stakeholders has not been done, however, during fieldwork we found it beneficial that TLF results could be demonstrated 
immediately for WP users. Different water sources can be compared and changes in water quality can be captured and shown in real time.

\section{Conclusion}

Efforts to improve risk assessment must consider the potential of new parameters such as TLF. A narrow focus on E. coli limits what is achievable with other knowledge and technologies. TLF and E. coli have different strengths and weaknesses as measures of microbial contamination risk. Incorporating both in sampling campaigns could improve risk estimation.

TLF has been shown to estimate risk corresponding with low/intermediate, high and very high $E$. coli risk classes, but with disagreement in $27 \%$ of samples (13\% estimating lower and $14 \%$ estimating higher risk than E. coli). Using E. coli as a reference, TLF is not able to distinguish intermediate risk from baseline conditions. However, TLF reflects in-situ conditions, minimizing method-induced variability and resulting in greater precision than culture-based methods provide. It also has a lower cost of sampling. When applied to typical groundwater (low-humic content, relatively consistent temperature, negligible turbidity and $\mathrm{pH}$ between 5 and 8), TLF may be well suited for a) pre-screening to effectively prioritize resources and b) high-frequency sampling to monitor and understand changes in risk. It also has potential as a real-time tool for communicating water quality concerns.

Further work should focus on understanding how TLF relates to pathogens and health outcomes, rather than focussing exclusively on its coincidence with E. coli. Better understanding of TLF behaviour in different groundwaters and software development for processing and presenting TLF data would also be key advancements. 


\section{Acknowledgements}

This research was supported by the British Natural Environment Research Council (NERC),

Economic and Social Research Council (ESRC) and Department for International Development (DFID) through Unlocking the Potential of Groundwater for the Poor (UPGro) Consortium Grant (NE/M008894/1; https://upgro.org/consortium/gro-for-good/). The TLF sensors were procured through UPGro capital grant CC16-059. The data that this publication refers to are available through Mendeley Data (http://dx.doi.org/10.17632/vt5ps2cnfc.1) and will also be posted on the National Geoscience Data Centre and the UK Data Archive. British Geological Survey authors publish with the permission of the Executive Director, British Geological Survey (NERC).

\section{References}

Agresti, A., 2010. Analysis of ordinal categorical data, 2nd ed. Wiley, Hoboken, USA.

Agresti, A., 1992. Analysis of Ordinal Paired Comparison Data. Appl. Stat. 41, 287-297.

Bain, R., Bartram, J., Elliott, M., Matthews, R., Mcmahan, L., Tung, R., Chuang, P., Gundry, S., 2012. A summary catalogue of microbial drinking water tests for low and medium resource settings. Int. J. Environ. Res. Public Health 9, 1609-1625. https://doi.org/10.3390/ijerph9051609

Bain, R., Cronk, R., Hossain, R., Bonjour, S., Onda, K., Wright, J., Yang, H., Slaymaker, T., Hunter, P., Pruss-Ustun, A., Bartram, J., 2014. Global assessment of exposure to faecal contamination through drinking water based on a systematic review. Trop. Med. Int. Heal. 19, 917-927. https://doi.org/10.1111/tmi.12334

Baker, A., 2001. Fluorescence excitation - emission matrix characterization of some sewage impacted rivers. Environ. Sci. Technol 35, 948-953. https://doi.org/10.1021/es000177t

Baker, A., Cumberland, S.A., Bradley, C., Buckley, C., Bridgeman, J., 2015. To what extent can portable fluorescence spectroscopy be used in the real-time assessment of microbial water quality? Sci. Total Environ. 532, 14-19. https://doi.org/10.1016/j.scitotenv.2015.05.114

Baker, A., Elliott, S., Lead, J.R., 2007. Effects of filtration and pH perturbation on freshwater organic matter fluorescence. Chemosphere 67, 2035-2043.

https://doi.org/10.1016/j.chemosphere.2006.11.024

BGS-DPHE, 2001. Arsenic contamination of groundwater in Bangladesh, in: Kinniburgh, D.G., Smedley, P.L. (Eds.), British Geological Survey Technical Report WC/00/19. British Geological Survey, Keyworth, UK.

Bieroza, M.Z., Heathwaite, A.L., 2016. Unravelling organic matter and nutrient biogeochemistry in groundwater-fed rivers under baseflow conditions: Uncertainty in in situ high-frequency analysis. Sci. Total Environ. 572, 1520-1533. https://doi.org/10.1016/j.scitotenv.2016.02.046 
Boehm, A.B., 2007. Enterococci concentrations in diverse coastal environments exhibit extreme variability. Environ. Sci. Technol. 41, 8227-8232. https://doi.org/10.1021/es071807v

Brennan, F.P., Abram, F., Chinalia, F.A., Richards, K.G., O'Flaherty, V., 2010a. Characterization of Environmentally Persistent Escherichia coli Isolates Leached from an Irish Soil. Appl. Environ. Microbiol. 76, 2175-2180. https://doi.org/10.1128/AEM.01944-09

Brennan, F.P., O'Flaherty, V., Kramers, G., Grant, J., Richards, K.G., 2010b. Long-term persistence and leaching of escherichia coli in temperate maritime soils. Appl. Environ. Microbiol. 76, 14491455. https://doi.org/10.1128/AEM.02335-09

Brown, J., Grammer, P., 2015. Indicators of microbial quality, in: Bartram, J., Baum, R., Coclanis, P., Gute, D., Kay, D., McFayden, S., Pond, K., Robertson, W., Rouse, M.J. (Eds.), Routlledge Handbook of Water and Health. Routledge, New York, USA, pp. 593-600.

Cangelosi, G.A., Meschke, J.S., 2014. Dead or alive: Molecular assessment of microbial viability. Appl. Environ. Microbiol. 80, 5884-5891. https://doi.org/10.1128/AEM.01763-14

Carstea, E.M., Bridgeman, J., Baker, A., Reynolds, D.M., 2016. Fluorescence spectroscopy for wastewater monitoring: A review. Water Res. 95, 205-219. https://doi.org/10.1016/j.watres.2016.03.021

Caswell, P. V., Baker, B.H., 1953. Geological Survey of Kenya Report No. 24: Geology of the Mombasa - Kwale Area, Degree Sheet 69 (with Coloured Map), with a Chapter on the Alkaline Igneous Comples at Jombo. Nairobi, Kenya.

CAWST, 2013. Introduction to Drinking Water Quality Testing. Calgary, Canada.

Chang, G.W., Brill, J., Lum, R., 1989. Proportion of beta-D-glucuronidase-negative Escherichia coli in human fecal samples. Appl Env. Microbiol 55, 335-339.

Christensen, R., 2015. Analysis of ordinal data with cumulative link models-estimation with the ordinal package. R-package version.

Cumberland, S., Bridgeman, J., Baker, A., Sterling, M., Ward, D., 2012. Fluorescence spectroscopy as a tool for determining microbial quality in potable water applications. Environ. Technol. 33, 687-693. https://doi.org/10.1080/09593330.2011.588401

Elliott, S., Lead, J.R., Baker, A., 2006. Characterisation of the fluorescence from freshwater, planktonic bacteria. Water Res. 40, 2075-2083. https://doi.org/10.1016/j.watres.2006.03.017

Ferguson, A.S., Layton, A.C., Mailloux, B.J., Culligan, P.J., Williams, D.E., Smartt, A.E., Sayler, G.S., Feighery, J., McKay, L.D., Knappett, P.S.K., Alexandrova, E., Arbit, T., Emch, M., Escamilla, V., Ahmed, K.M., Alam, M.J., Streatfield, P.K., Yunus, M., van Geen, A., 2012. Comparison of fecal indicators with pathogenic bacteria and rotavirus in groundwater. Sci. Total Environ. 431, 314322. https://doi.org/10.1016/j.scitotenv.2012.05.060

Ferguson, A.S., Mailloux, B.J., Ahmed, K.M., Van Geen, A., McKay, L.D., Culligan, P.J., 2011. Handpumps as reservoirs for microbial contamination of well water. J. Water Health 9, 708-717. https://doi.org/10.2166/wh.2011.106

Fox, B.G., Thorn, R.M.S., Anesio, A.M., Reynolds, D.M., 2017. The in situ bacterial production of fluorescent organic matter; an investigation at a species level. Water Res. 125, 350-359. https://doi.org/10.1016/j.watres.2017.08.040

Fujioka, R., Sian-Denton, C., Borja, M., Castro, J., Morphew, K., 1998. Soil: the environmental source of Escherichia coli and Enterococci in Guam's streams. J. Appl. Microbiol. 85 Suppl 1, 83S-89S. https://doi.org/10.1111/j.1365-2672.1998.tb05286.x

Garcia-Armisen, T., Prats, J., Servais, P., 2007. Comparison of culturable fecal coliforms and 
Escherichia coli enumeration in freshwaters. Can. J. Microbiol. 53, 798-801.

https://doi.org/10.1139/W07-033

Gooddy, D.C., Hinsby, K., 2008. Organic Quality of Groundwaters, in: Edmunds, W.M., Shand, P. (Eds.), Natural Groundwater Quality. Blackwell, Oxford, UK, pp. 59-70. https://doi.org/10.1002/9781444300345.ch3

Gronewold, A.D., Sobsey, M.D., McMahan, L., 2017. The compartment bag test (CBT) for enumerating fecal indicator bacteria: Basis for design and interpretation of results. Sci. Total Environ. https://doi.org/http://dx.doi.org/10.1016/j.scitotenv.2017.02.055

Guerrant, R.L., Kosek, M., Lima, A.A.M., Lorntz, B., Guyatt, H.L., 2002. Updating the DALYs for diarrhoeal disease. Trends Parasitol. 18, 191-193. https://doi.org/10.1016/S14714922(02)02253-5

Haller, L., Poté, J., Loizeau, J.L., Wildi, W., 2009. Distribution and survival of faecal indicator bacteria in the sediments of the Bay of Vidy, Lake Geneva, Switzerland. Ecol. Indic. 9, 540-547. https://doi.org/10.1016/j.ecolind.2008.08.001

Hamilton, W.P., Kim, M., Thackston, E.L., 2005. Comparison of commercially available Escherichia coli enumeration tests: Implications for attaining water quality standards. Water Res. 39, 48694878. https://doi.org/10.1016/j.watres.2005.02.006

Heibati, M., Stedmon, C.A., Stenroth, K., Rauch, S., Toljander, J., Säve-Söderbergh, M., Murphy, K.R., 2017. Assessment of drinking water quality at the tap using fluorescence spectroscopy. Water Res. 125, 1-10. https://doi.org/10.1016/j.watres.2017.08.020

Henderson, R.K., Baker, A., Murphy, K.R., Hambly, A., Stuetz, R.M., Khan, S.J., 2009. Fluorescence as a potential monitoring tool for recycled water systems: A review. Water Res. 43, 863-881. https://doi.org/10.1016/j.watres.2008.11.027

Hollander, M., Wolfe, D.A., Chicken, E., 2014. Nonparametric Statistical Methods, 3rd ed. Wiley, [online].

Hudson, N., Baker, A., Reynolds, D., 2007. Fluorescence Analysis of Dissolved Organic Matter in Natural, Waste and Polluted Waters - A Review. River Res. Appl. 22, 1085-1095. https://doi.org/10.1002/rra

Hudson, N., Baker, A., Ward, D., Reynolds, D.M., Brunsdon, C., Carliell-Marquet, C., Browning, S., 2008. Can fluorescence spectrometry be used as a surrogate for the Biochemical Oxygen Demand (BOD) test in water quality assessment? An example from South West England. Sci. Total Environ. 391, 149-158. https://doi.org/10.1016/j.scitotenv.2007.10.054

JMP, 2017. Progress on Drinking Water, Sanitation and Hygiene: 2017 Update and SDG Baselines (launch version July 12,2017). [online].

Kendall, M.G., 1938. A New Measure of Rank Correlation. Biometrika 30, 81-93.

Khamis, K., Sorensen, J.P.R., Bradley, C., Hannah, D.M., Lapworth, D.J., Stevens, R., 2015. In situ tryptophan-like fluorometers: assessing turbidity and temperature effects for freshwater applications. Environ. Sci. Process. Impacts 17, 740-52. https://doi.org/10.1039/c5em00030k

Kirchman, D.L., Sigda, J., Kapuscinski, R., Mitchell, R., 1982. Statistical analysis of the direct count for enumerating bacteria. Appl. Environ. Microbiol. 44, 376-382.

Lapworth, D.J., Gooddy, D.C., Allen, D., Old, G.H., 2009. Understanding groundwater, surface water, and hyporheic zone biogeochemical process in a Chalk catchment using fluorescence properties of dissolves and colloidal organic matter. J. Geophys. Res. Biogeosciences 114, 1-10. https://doi.org/10.1029/2009JG000921 
Lapworth, D.J., Gooddy, D.C., Butcher, A.S., Morris, B.L., 2008. Tracing groundwater flow and sources of organic carbon in sandstone aquifers using fluorescence properties of dissolved organic matter (DOM). Appl. Geochemistry 23, 3384-3390. https://doi.org/10.1016/j.apgeochem.2008.07.011

Lawrence, A.R., Macdonald, D.M.J., Howard, A.G., Barrett, M.H., Pedley, S., Ahmed, K.M., Nalubega, M., 2001. Guidelines for Assessing the Risk to Groundwater from On-Site Sanitation, ARGOSS British Geological Survey Commissioned Report.

Leclerc, H., Mossel, D. a, Edberg, S.C., Struijk, C.B., 2001. Advances in the bacteriology of the coliform group: their suitability as markers of microbial water safety. Annu. Rev. Microbiol. 55, 201-34. https://doi.org/10.1146/annurev.micro.55.1.201

Levy, K., 2015. Editorial: Does poor water quality cause diarrheal disease? Am. J. Trop. Med. Hyg. 93, 899-900. https://doi.org/10.4269/ajtmh.15-0689

Mumma, A., Lane, M., Kairu, E., Tuinhof, A., Hirji, R., 2011. Kenya Groundwater Governance Case Study. Water Partnersh. Progr. Water Pap.

Murphy, H.M., Prioleau, M.D., Borchardt, M.A., Hynds, P.D., 2017. Review: Epidemiological evidence of groundwater contribution to global enteric disease, 1948--2015. Hydrogeol. J. 25, 981-1001. https://doi.org/10.1007/s10040-017-1543-y

Okotto-Okotto, J., Okotto, L., Price, H., Pedley, S., Wright, J., 2015. A longitudinal study of long-term change in contamination hazards and shallow well quality in two neighbourhoods of Kisumu, Kenya. Int. J. Environ. Res. Public Health 12, 4275-4291. https://doi.org/10.3390/ijerph120404275

Osborn, M.J., Trussell, R.R., Deleon, R., Fung, D.Y.C., Haas, C.N., Levy, D.A., Mcarthur, J.V., Rose, J.B., Sobsey, M.D., Walt, D.R., Weisberg, S.B., Yates, M. V, 2004. Indicators for Waterborne Pathogens. The National Academies Press, Washington, USA.

Pote, J., Haller, L., Kottelat, R., Sastre, V., Arpagaus, P., Wildi, W., 2009. Persistence and growth of faecal culturable bacterial indicators in water column and sediments of Vidy Bay, Lake Geneva, Switzerland. J. Environ. Sci. 21, 62-69. https://doi.org/10.1016/S1001-0742(09)60012-7

Prüss-Ustün, A., Bartram, J., Clasen, T., Colford, J.M., Cumming, O., Curtis, V., Bonjour, S., Dangour, A.D., De France, J., Fewtrell, L., Freeman, M.C., Gordon, B., Hunter, P.R., Johnston, R.B., Mathers, C., Mäusezahl, D., Medlicott, K., Neira, M., Stocks, M., Wolf, J., Cairncross, S., 2014. Burden of disease from inadequate water, sanitation and hygiene in low- and middle-income settings: A retrospective analysis of data from 145 countries. Trop. Med. Int. Heal. 19, 894-905. https://doi.org/10.1111/tmi.12329

Reynolds, D.M., 2003. Rapid and direct determination of tryptophan in water using synchronous fluorescence spectroscopy. Water Res. 37, 3055-3060. https://doi.org/10.1016/S00431354(03)00153-2

Reynolds, D.M., Ahmad, S.R., 1995. The effect of metal ions on the fluorescence of sewage wastewater. Water Res. 29, 2214-2216. https://doi.org/10.1016/0043-1354(95)00046-N

Roser, D., Ashbolt, N., 2007. Source Water Quality Assessment and the Management of Pathogens in Surface Catchments and Aquifers, Research Report 29. Salisbury, Australia.

Schmid-Hempel, P., 2011. Evolutionary Parasitology: The Integrated Study of Infections, Immunology, Ecology, and Genetics. Oxford University Press, Oxford, UK.

Seredyńska-Sobecka, B., Baker, A., Lead, J.R., 2007. Characterisation of colloidal and particulate organic carbon in freshwaters by thermal fluorescence quenching. Water Res. 41, 3069-3076. https://doi.org/10.1016/j.watres.2007.04.017 
Solo-Gabriele, H.M., Wolfert, M.A., Desmarais, T.R., Palmer, C.J., 2000. Sources of Escherichia coli in a coastal subtropical environment. Appl. Environ. Microbiol. 66, 230-237.

https://doi.org/10.1128/AEM.66.1.230-237.2000

Sorensen, J.P.R., Baker, A., Cumberland, S.A., Lapworth, D.J., MacDonald, A.M., Pedley, S., Taylor, R.G., Ward, J.S.T., 2018a. Real-time detection of faecally contaminated drinking water with tryptophan-like fluorescence: defining threshold values. Sci. Total Environ. 622-623, 12501257. https://doi.org/10.1016/j.scitotenv.2017.11.162

Sorensen, J.P.R., Lapworth, D.J., Marchant, B.P., Nkhuwa, D.C.W., Pedley, S., Stuart, M.E., Bell, R.A., Chirwa, M., Kabika, J., Liemisa, M., Chibesa, M., 2015a. In-situ tryptophan-like fluorescence: A real-time indicator of faecal contamination in drinking water supplies. Water Res. 81, 38-46. https://doi.org/10.1016/j.watres.2015.05.035

Sorensen, J.P.R., Lapworth, D.J., Read, D.S., Nkhuwa, D.C.W., Bell, R.A., Chibesa, M., Chirwa, M., Kabika, J., Liemisa, M., Pedley, S., 2015b. Tracing enteric pathogen contamination in subSaharan African groundwater. Sci. Total Environ. 538, 888-895. https://doi.org/10.1016/j.scitotenv.2015.08.119

Sorensen, J.P.R., Sadhu, A., Sampath, G., Sugden, S., Dutta Gupta, S., Lapworth, D.J., Marchant, B.P., Pedley, S., 2016. Are sanitation interventions a threat to drinking water supplies in rural India? An application of tryptophan-like fluorescence. Water Res. 88, 923-932. https://doi.org/10.1016/j.watres.2015.11.006

Sorensen, J.P.R., Vivanco, A., Ascott, M.J., Gooddy, D.C., Lapworth, D.J., Read, D.S., Rushworth, C.M., Bucknall, J., Herbert, K., Karapanos, I., Gumm, L.P., Taylor, R.G., 2018b. Online fluorescence spectroscopy for the real-time evaluation of the microbial quality of drinking water. Water Res. 137, 301-309. https://doi.org/10.1016/j.watres.2018.03.001

Stauber, C., Miller, C., Cantrell, B., Kroell, K., 2014. Evaluation of the compartment bag test for the detection of Escherichia coli in water. J. Microbiol. Methods 99. https://doi.org/10.1016/j.mimet.2014.02.008

Stedmon, C. a., Seredyńska-Sobecka, B., Boe-Hansen, R., Le Tallec, N., Waul, C.K., Arvin, E., 2011. A potential approach for monitoring drinking water quality from groundwater systems using organic matter fluorescence as an early warning for contamination events. Water Res. 45, 6030-6038. https://doi.org/10.1016/j.watres.2011.08.066

Tabak, M., Sartor, G., Cavatorta, P., 1989. On the interactions of metal ions with tryptophan and glyciltryptophan: A fluorescence study. J. Lumin. 43, 355-361. https://doi.org/10.1016/00222313(89)90038-0

UNICEF, 2017. Target Product Profile: Rapid E. coli Detection.

Wang, A., McMahan, L., Rutstein, S., Stauber, C., Reyes, J., Sobsey, M.D., 2017. Household microbial water quality testing in a peruvian demographic and health survey: Evaluation of the compartment bag test for Escherichia coli. Am. J. Trop. Med. Hyg. 96, 970-975. https://doi.org/10.4269/ajtmh.15-0717

Wang, Z., Cao, J., Meng, F., 2015. Interactions between protein-like and humic-like components in dissolved organic matter revealed by fluorescence quenching. Water Res. 68, 404-413. https://doi.org/10.1016/j.watres.2014.10.024

Wehry, E.L., 1973. Effects of Molecular Structure and Molecular Environment on Fluorescence, in: Guibault, G.G. (Ed.), Practical Fluorescence: Theory, Methods, and Techniques. Marcel Decker, New York, USA, pp. 79-136.

WHO, 2012. Rapid asssessment of drinking-water quality: a handbook for implementation. Geneva, Switzerland. 
WHO, 2011. Guidelines for Drinking-water Quality, 4th ed. WHO Press, Geneva, Switzerland. https://doi.org/10.1016/S1462-0758(00)00006-6

Yamashita, Y., Jaffé, R., 2008. Characterizing the interactions between trace metals and dissolved organic matter using excitation - emission matrix and parallel factor analysis. Environ. Sci.

Technol. 42, 7374-7379. 
Table 1 Summary of sanitary inspection scores for selected water points

\begin{tabular}{l|l|l} 
WP Type & No. of Sites Selected & SI Score (median and range) \\
\hline borehole with handpump (BH) & 11 & $2.5(1-5)$ \\
\hline covered well with handpump (CW) & 14 & $3(0-7)$ \\
\hline open well (OW) & 12 & $6(2-9)$
\end{tabular}


Table 2 Sample analysis methods and counts (including duplicates and replicates)

\begin{tabular}{l|l|l|l|l|l} 
Indicator & Method & Manufacturer & $\begin{array}{l}\text { Total } \\
\text { Samples }\end{array}$ & Dups & Reps \\
\hline TLF & In-situ fluorimetry & CTG, Surrey, UK & 291 & 129 & 0 \\
\hline E. coli & CBTs & Aquagenx, North Carolina, USA & 410 & 96 & 72 \\
\hline E. coli & $\begin{array}{l}\text { PC (m-ColiBlue24 } \\
\text { broth) }\end{array}$ & Hach, Colorado, USA & 176 & 52 & 54 \\
\hline TTCs & $\begin{array}{l}\text { PC (laurel sulphate } \\
\text { broth) }\end{array}$ & DelAgua, Surrey, UK & 203 & 21 & 21
\end{tabular}


Table 3 Results of Kendall's $\tau$ tie-corrected rank correlations and cumulative link models (including post-hoc likelihood ratio and symmetry tests)

\begin{tabular}{l|l|l|l|l|l|l|l|l} 
Comparison & $\mathrm{n}$ & $\begin{array}{l}\text { Kendall's } \\
\text { correlation } \\
\text { coefficient }\end{array}$ & $\begin{array}{l}\text { CLM } \\
\text { effect } \\
\text { estimate }\end{array}$ & $\begin{array}{l}\text { CLM } \\
\text { standard } \\
\text { error }\end{array}$ & $\begin{array}{l}\text { CLM } \\
p \text { value }\end{array}$ & $\begin{array}{l}\text { LRT } \\
\text { ratio }\end{array}$ & $\begin{array}{l}\text { LRT } \\
p \text { value }\end{array}$ & $\begin{array}{l}\text { Symmetry } \\
\text { test } \\
p \text { value }\end{array}$ \\
\hline $\begin{array}{l}\text { TLF and } \\
\text { E. coli }(\mathrm{CBT})\end{array}$ & 162 & 0.59 & 0.01 & 0.21 & 0.98 & 0.2 & 0.68 & $>0.05$ \\
\hline $\begin{array}{l}\text { TLF and } \\
\text { E. coli }(\mathrm{PC})\end{array}$ & 70 & 0.59 & 0.61 & 0.32 & 0.05 & 10 & 0.001 & $\begin{array}{l}<0.05 ; \\
0.5 ; 0.45\end{array}$ \\
\hline $\begin{array}{l}\text { TTCs and } \\
\text { TLF }\end{array}$ & 81 & 0.57 & 1.50 & 0.32 & $<0.001$ & 0.7 & 0.41 & $<0.05$ \\
\hline $\begin{array}{l}\text { TTCs and } E . \\
\text { coli } \text { (CBT) }\end{array}$ & 161 & 0.74 & 1.16 & 0.21 & $<0.001$ & 8.1 & 0.02 & $\begin{array}{l}<0.05 \text { or } \\
\text { undefined }\end{array}$ \\
\hline $\begin{array}{l}\text { E. coli } \text { (PC } \\
\text { and CBT })\end{array}$ & 70 & 0.74 & -0.09 & 0.31 & 0.78 & 2.6 & 0.28 & $\begin{array}{l}>0.05 \text { or } \\
\text { undefined }\end{array}$
\end{tabular}


Table 4 Sample counts and disagreement for TLF vs. E. coli (CBT) risk classifications

\begin{tabular}{|c|c|c|c|c|c|c|}
\hline & & \multicolumn{3}{|c|}{ TLF Risk } & \multicolumn{2}{|c|}{ TLF Disagreement } \\
\hline & & Low & Medium & High & {$[-]$} & {$[+]$} \\
\hline \multirow[t]{3}{*}{ E. coli Risk } & Low/Int & 59 & 14 & 1 & -- & $20 \%$ \\
\hline & High & 11 & 24 & 8 & $26 \%$ & $19 \%$ \\
\hline & Very high & 2 & 8 & 35 & $22 \%$ & -- \\
\hline \multirow{2}{*}{$\begin{array}{l}\text { E. coli } \\
\text { Disagreement }\end{array}$} & {$[-]$} & -- & $30 \%$ & & & \\
\hline & {$[+]$} & $18 \%$ & $17 \%$ & & & \\
\hline
\end{tabular}


Highlights:

- Tryptophan-like fluorescence (TLF) can complement E. coli as a risk indicator.

- Both TLF and E. coli distinguish low/intermediate, high and very high risk sources.

- TLF has negligible method-induced variability, unlike bacteriological analyses.

- TLF is useful for pre-screening, monitoring and demonstrating risk in groundwater. 


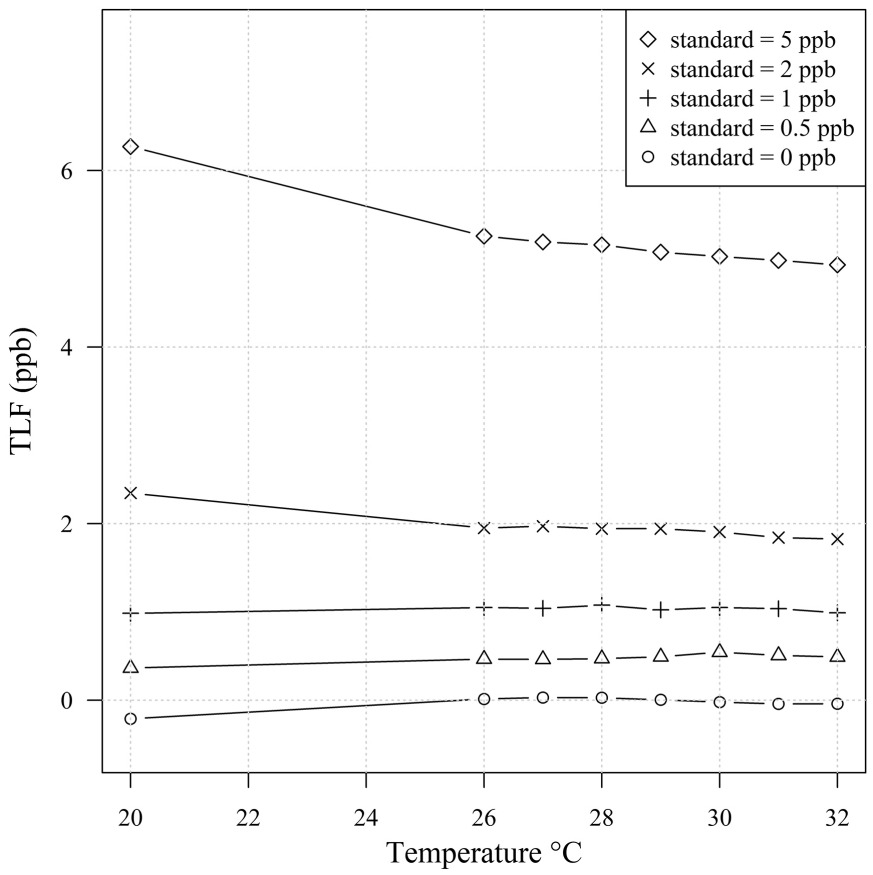

Figure 1 


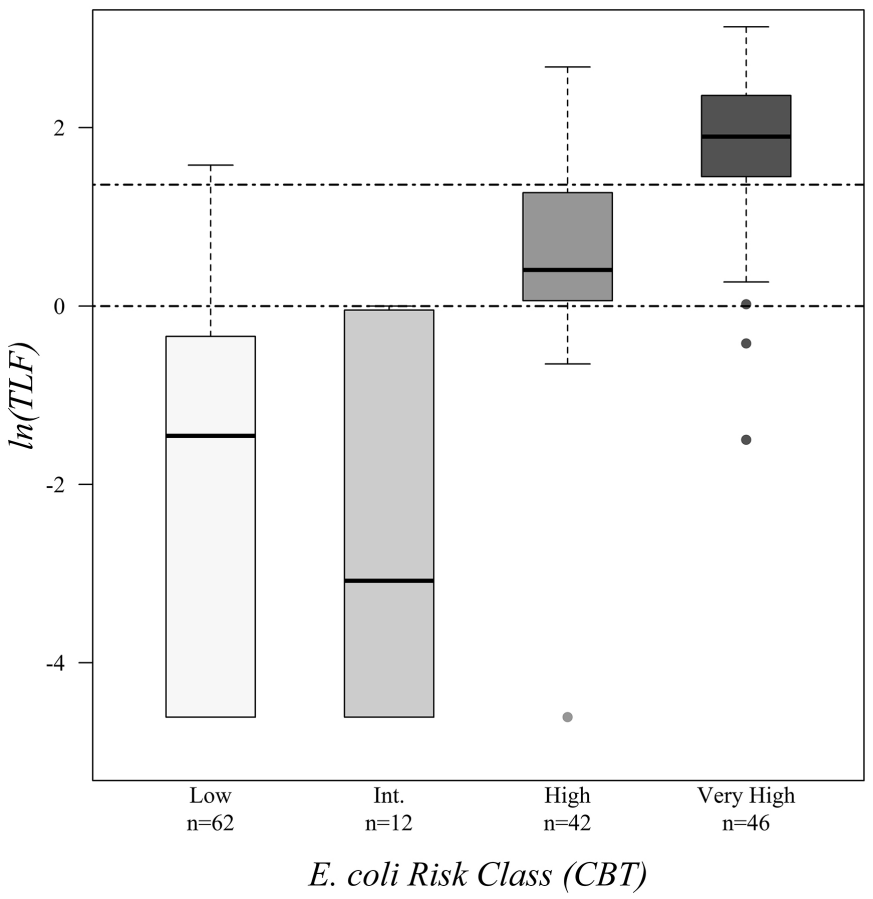

Figure 2 
a.

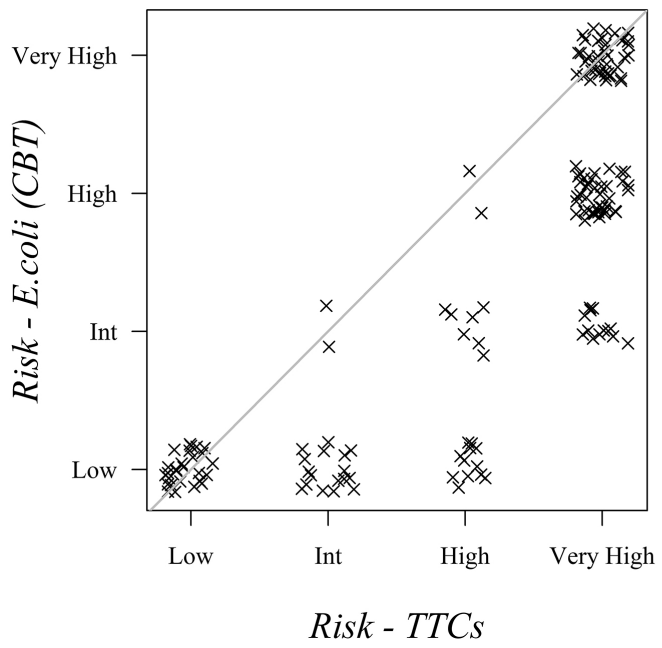

b.

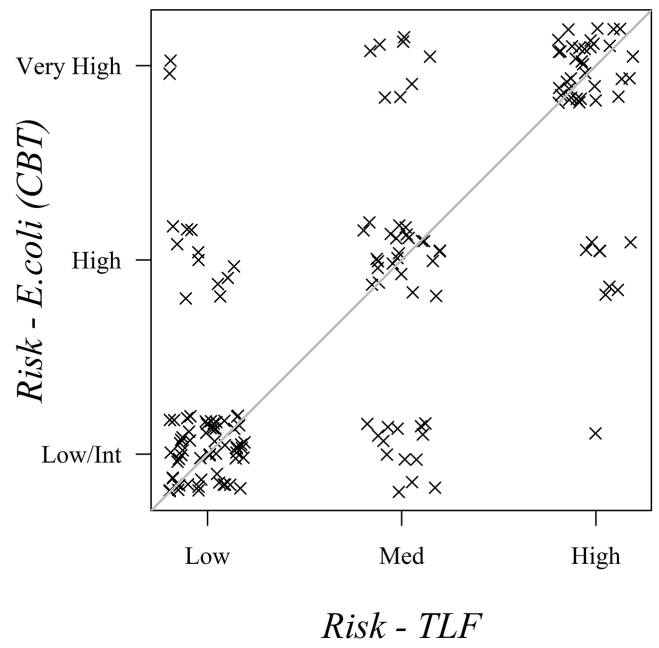

Figure 3 


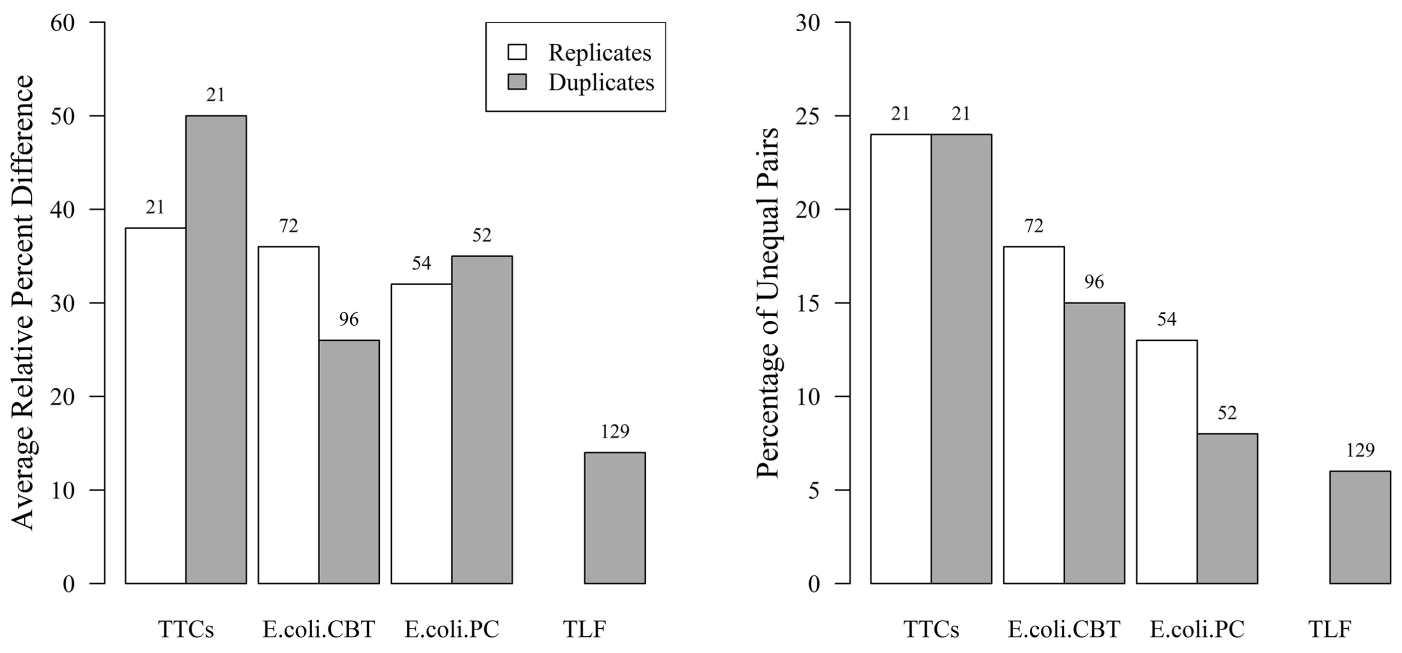

Figure 4 
Wet versus Dry Season Comparison of Values

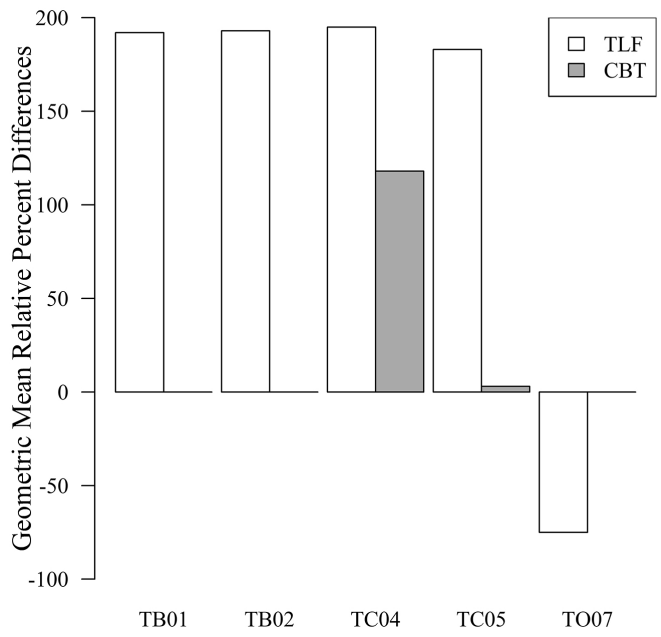

Wet versus Dry Season Comparison of Risk Classes

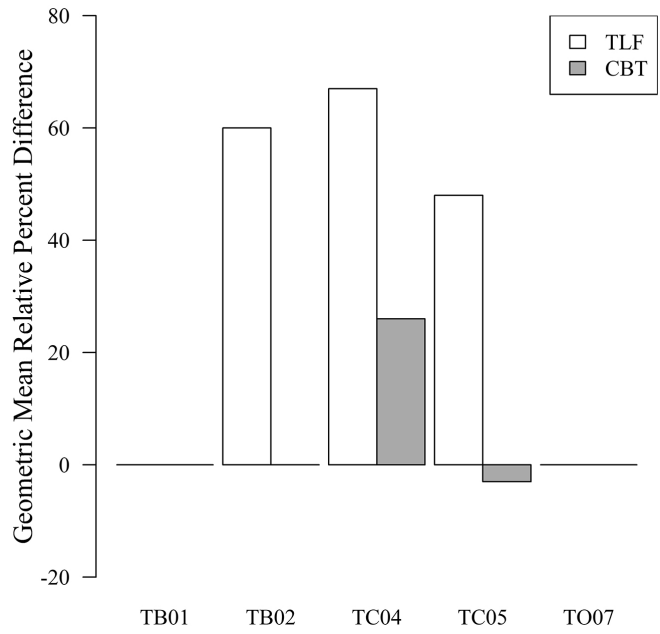

Figure 5 